- says a prominent Florida scientist. "But senior faculty raised eyebrows that his work was not well replicated," he says.

The separate case of Timothy $\mathbf{J}$. Baldwin shows the difficulty of uncovering problems that may follow researchers moving internationally between scientific institutions. After receiving his doctorate in biology in 1985 from University College London, Baldwin went to the Massachusetts Institute of Technology (MIT) as a postdoctoral fellow in the NIH-funded laboratory of Steven J. Burden, a neuroscientist.

Whilst at MIT, those working in Burden's laboratory, including Baldwin, were investigated following sabotage to experiments, but no-one was found responsible. Baldwin left in August 1989 for a postdoctoral position at the University of California in San Francisco (UCSF). About two months after he left Massachusetts, MIT records say, Baldwin was asked to return because some molecular biology experiments he had conducted for an article published with Burden (see Nature 341, 716; 1989) could not be reproduced.

Baldwin went back to MIT, attempted unsuccessfully to repeat the experiments one day and then admitted himself to a mental hospital, MIT records say. After leaving hospital, Baldwin returned to research at UCSF, where officials were unaware of what had unfolded in Boston.

These events prompted Burden to retract a major part of the published study (see Nature 345, 364; 1990) and caused MIT to initiate an investigation into possible misconduct. This probe became a contentious affair between Baldwin and Burden. MIT decided in 1992 that it could not conclusively establish whether Baldwin had falsified the research results, largely as his laboratory notebooks had disappeared.

NIH officials reached the same conclusion. But they added in a separate report that Burden did not engage in scientific misconduct and acted properly in exposing the claims by Baldwin that could not be supported. The NIH report also expressed reservations about the fairness and objectivity of MIT's handling of Burden's complaint.

Kenneth D. Campbell, a spokesman for MIT, insists that Burden was treated fairly. "There was no bias against Burden at MIT, as asserted by the OSI [the predecessor of ORI]," he says. Burden subsequently left MIT for New York University.

Problems with the sabotage of experiments also occurred at UCSF in the laboratory of Lily J. Jan, where Baldwin worked for four years after leaving MIT. Baldwin was investigated with others by UCSF at the time, as he was one of those working in the laboratory, but the investigation did not find who was responsible.

After he left UCSF early in 1994, Baldwin returned to the United Kingdom, taking up a position in the experimental pathology division at Guy's Hospital in London. But problems arose there. Baldwin acknowledges resigning his research position at Guy's in September 1995 while he was under investigation for harassing a colleague by sending him offensive sexual material.

Guy's Hospital spokeswoman Carol Meads declines to discuss Baldwin's case, except to note that the hospital has policies for checking the references of all applicants. Baldwin says he resigned from Guy's during the investigation because "it was obvious I was not getting a fair shake". He acknowledges he sent the offensive material, but declines further comment.

At Glaxo Wellcome's Geneva Biomedical Research Institute, the director, Jonathan K. C. Knowles, says he knew that he was hiring a scientist with a troubled past when he employed Annemarie Surprenant, a neurophysiologist, in late 1993.

Officials at Oregon Health Sciences University in Portland had found in 1992 that Surprenant falsely claimed in three grant applications to the NIH that she earned a medical degree in 1976 from the University

\section{Private investigators track down fraudsters}

London. A former British police detective and a medical doctor have turned 'fraudbusters' and set up a private agency to investigate fraud and misconduct in clinical research, particularly that related to the testing of drugs.

Medico-Legal Investigations is offering to conduct investigations into possible research and other fraud in health service trusts, health authorities and the pharmaceutical industry. It is run by Frank Wells, former director of medical affairs for the Association of the British Pharmaceutical Industry, and Peter Jay, a former police detective.

Jay has since been investigating fraud and other malpractice for the solicitors to the General Medical and Dental Councils, while Wells is the author of a text- book on medical research fraud. The pair claim in their publicity brochure to be able to achieve "faster results" than more conventional procedures, to defuse "delicate situations" and to turn around "adverse press criticism".

But the prospect of latter-day Sherlock Holmeses using magnifying glasses to examine laboratory notebooks has been met with some nervousness in the medical community. David London, for example, registrar of the Royal College of Physicians of London, says that he is cautious about the idea, which has not says that he would prefer to see the agency brought under "the umbrella of an official body, rather than [being] freelance". yet been discussed at the college. He

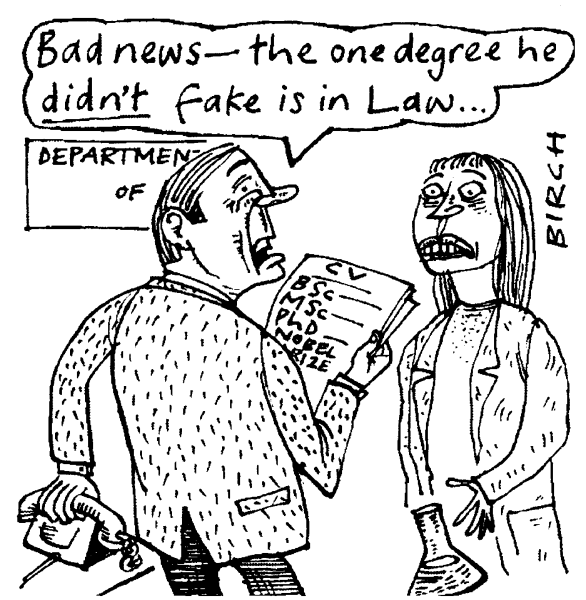

of Illinois at Chicago. There was no record of her having attended that university. She received her doctorate in physiology in 1979 from Monash University in Australia.

It was learned during the Oregon probe that Surprenant had falsely stated that she had a medical degree when she was hired for a job at MIT in 1983. The Oregon report says Surprenant was recruited to MIT by R. Alan North, a British-born neuroscientist who is now her husband.

In May 1994, Surprenant acknowledged scientific misconduct in an ORI settlement agreement, which barred her from receiving US government grants for three years. In an interview, she at first said the false listing of a medical degree on her CV was "a clerical error". Then she acknowledged that she "had made a mistake".

"I thought I had a medical degree," said Surprenant. But, she added, the difficulties in the US are irrelevant. "I signed the ORI settlement to put this away, so my research could continue. I stand behind every piece of research I have ever done."

Knowles says Surprenant and North moved as a research team to Geneva, and he has been extremely happy with their work. "My job is not to supervise the scientific establishment of the United States," Knowles says. "My job is to maintain a high standard of science at this institute." He argues the NIH acted properly and well in Surprenant's case. "Obviously, mistakes were made. I was interested in having (Surprenant) do another job. She does it well."

Whatever the circumstances surrounding individual cases, an increasing number of scientists feel that more effective procedures are needed by which scientific institutions can communicate freely - and in confidence - about the past behaviour of researchers without the risk of litigation.

"Sooner or later most large institutions have to deal with this kind of problem," says Raff. "There are powerful forces on individuals to keep this type of thing quiet," he says, arguing that it is not in the interests of research group leaders, for example, to publicize misconduct that has occurred in their own laboratory. "But it cannot go on like this. We need ways to protect institutions and scientists." 